\title{
Characterization of Microemulsions Prepared using Isopropyl Palmitate with various Surfactants and Cosurfactants
}

\author{
Hussam S Basheer ${ }^{1}$, Mohamed Ibrahim Noordin ${ }^{1}$ and Mowafaq M Ghareeb ${ }^{2 \star}$ \\ ${ }^{1}$ Department of Pharmacy, Faculty of Medicine, University of Malaya, Kuala Lumpur, Malaysia, ${ }^{2}$ Department of Pharmaceutics, \\ College of Pharmacy, Baghdad University, Baghdad, Iraq
}

${ }^{*}$ For correspondence: Email: mopharmacy@yahoo.com; Tel: 009647901737638

Revised accepted: 4 May 2013

\begin{abstract}
Purpose: To investigate the effect of various surfactants and cosurfactants, and their ratio on microemulsions prepared with isopropyl palmitate (IPP)

Methods: Tween 20, 40, 60, and 80 were used separately as surfactant with methanol, ethanol, 1propanol, 1-butanol or 1-pentanol as cosurfactant, and IPP as oil phase to prepare various microemulsions. Various surfactant to cosurfactant ratios (1:1, 2:1, 3:1, 4:1, and 1:0) were used in the preparation. Pseudoternary phase diagram was used to define the microemulsion area, and samples from the best combinations, i.e., those that produced the largest volume of microemulsion, were subjected to further characterization by polarized light microscopy, differential scanning calorimetry (DSC), zetasizer, rheometer, and for stability.

Results: Based on the microemulsion areas produced in the pseudoternary phase diagrams, the the surfactants were ranked in the following order of effectiveness: Tween $80>60>40>20$ while the alcohols (co-surfactants) were ranked as follows: 1-butanol $>1$-pentanol $>1$-propanol $>$ ethanol $=$ methanol. The best surfactant to cosurfactant ratio for microemulsion preparation was 3:1.

Conclusion: The selected surfactant/co-surfactant combination (i.e., Tween 80:1-butanol, 3:1) produces a stable microemulsion possesses a good potential as a drug delivery system
\end{abstract}

Keywords: Microemulsion, Palm oil, Thermal analysis, Tween 80, Alcohol

Tropical Journal of Pharmaceutical Research is indexed by Science Citation Index (SciSearch), Scopus, International Pharmaceutical Abstract, Chemical Abstracts, Embase, Index Copernicus, EBSCO, African Index Medicus, JournalSeek, Journal Citation Reports/Science Edition, Directory of Open Access Journals (DOAJ), African Journal Online, Bioline International, Open-J-Gate and Pharmacy Abstracts

\section{INTRODUCTION}

Microemulsion can be defined as a system of water, oil and an amphiphile which is a single optically isotropic and thermodynamically stable liquid solution [1]. Hoar and Schulman stimulated the interest of researchers in microemulsions in 1943 when they found that the addition of a strong surface-active agent resulted in emulsions of oil and water without vigorous shaking [2]. Although there is similarity between emulsion and microemulsion, the latter vary in that the average drop size does not grow with time like conventional emulsion due to thermodynamic stability [3]. The clear appearance of microemulsion is another difference in comparison to the emulsion which is turbid. The droplet sizes of the dispersed phase in microemulsions are around $10 \mathrm{~nm}$ [4]. An additional difference is in the shape of the particles dispersed in the continuous phase; emulsions consist of roughly spherical droplets of one phase dispersed into the other while microemulsions constantly evolve between 
various structures ranging from droplet-like swollen micelles to bicontinuous structures [5].

Microemulsion technology is applied in the cosmetic and pharmaceutical industry in the formulation of transdermal drug delivery systems and some topical preparations because of their potential to increase the permeation of drug across diffusion layers, good appearance, and drug solubilization.

In 2008, Malaysia produced 17.7 million tons of palm oil and was the second largest producer of palm oil [6]. Palmitic acid is the main fatty acid content of palm oil from which isopropyl palmitate is derived [6]. The low cost and availability of palm oil-derived isopropyl palmitate make it a good candidate to incorporate in microemulsion production as oil phase.

For microemulsions, once the conditions are right, spontaneous formation occurs. As for simple aqueous systems, microemulsion formation is dependent on surfactant type and structure.

The surfactants can be employed to stabilize oilin-water dispersions through orientation of the molecules at the interface and significantly lowering interfacial free energy [7]. Meanwhile, the interfacial free energy reduces according to the type and concentration of surfactant. The thermodynamic stability is obtained when nearzero interfacial tension is achieved. Several factors have been indicated to affect the formation of microemulsions such as the ratio of surfactant to cosurfactant, the chain-length of the cosurfactant, the type of hydrocarbon in the oil phase, as well as the temperature during the preparation and phase inversion.

The aim of this work was to investigate the effect of type and ratio of surfactant and cosurfactant mixtures on the preparation of suitable microemulsion using palm oil-derived IPP.

\section{EXPERIMENTAL}

\section{Materials}

Isopropyl palmitate (IPP) was obtained from Malaysian Palm Oil Association (Malaysia). Tweens (20, 40, 60, and 80), methanol, ethanol, propanol, butanol, and pentanol $99.5 \%$ were obtained from $R$ \& $M$ Chemicals. Sdn. Bhd (Malaysia). All other chemicals used were of analytical grade.

\section{Phase behavior study}

The water titration method was employed to study the phase behavior of the prepared systems [8]. At $25{ }^{\circ} \mathrm{C}$, water was increasingly added in approximately $5 \%(\mathrm{w} / \mathrm{w})$ increment, in a screw capped tube to the oil phase (IPP), surfactant(s), and cosurfactant mixture, with simple stirring using a magnetic stirrer for $5 \mathrm{~min}$. Eq 1 was used to define the mixture compositions at different points in the phase diagrams.

$\% \mathrm{SM}+\% \mathrm{O}+\% \mathrm{~W}=100 \%$

where SM is surfactant/cosurfactant mixture, $\mathrm{O}$ is oil phase and $\mathrm{W}$ is water (aqueous phase).

\section{Effect of surfactants and cosufactants}

Tween 20, 40, 60, and 80 were incorporated separately in the preparations to study the influence of the type of surfactants with 1-butanol as cosurfactant at ratio of $1: 1$, while the effect of the cosurfactant types (methanol, ethanol, 1propanol, 1-butanol and 1-pentanol) were investigated with Tween 80 as surfactant at ratio of $1: 1$.

The effects of surfactant: cosurfactant (Tween $80: 1$-butanol) ratio on the area of microemulsion in the phase diagram were investigated at ratios $(1: 1,2: 1,3: 1,4: 1$, and $1: 0)$.

\section{Preparation of samples}

The microemulsions were prepared using the best combination with isopropyl palmitate as oil at percentage obtained from preliminary studies by diluting the combination of oil and surfactant mixture with water using a magnetic stirrer for 5 minutes. The ratio surfactant to cosurfactant was $3: 1$. The concentration of water varied from 5 to $50 \% \mathrm{w} / \mathrm{w}$ in $5 \%$ increment. The mixture turned from turbid through opaque to a translucent yellow mixture and this marked the formation of a microemulsion.

Ten samples were then selected from the optimum combination at the line on the pseudoternary phase diagram. The samples had composition of water/IPP/surfactant mixture as follows: sample 1- $(5 / 50 / 45), 2-(10 / 45 / 45), 3-$ $(15 / 40 / 45), \quad 4-(20 / 35 / 45), \quad 5-(25 / 30 / 45), 6-$ $(30 / 25 / 45), \quad 7-(35 / 20 / 45), \quad 8-(40 / 15 / 45)$, $9-$ $(45 / 10 / 45)$, and 10- (50/5/45). 


\section{Appearance}

The samples were observed for their appearance visually and also microscopically using a polarized light microscope (Leica model PM RXP, New York) with a JVC Colour Video camera at $100 \times$ magnification [9].

\section{Determination of microemulsion type}

For differentiating the type of microemulsion, conductivity measurement (Mettler Toledo MC 226) and microscopic observation using water or oil soluble dye [10] were carried out.

\section{Rheology study}

The rheological properties of the microemulsions were investigated using a Bohlin CVOR (Creep, Viscosity, Oscillation, Relaxation) rheometer (Malvern Instruments, UK) equipped with Bohlin software and thermostatic control system (Bohlin KTB30, Malvern, UK). The rheometer consisted of a thermostatically controlled cone and plate tool. The temperature was maintained at $25 \pm 0.5$ ${ }^{\circ} \mathrm{C}$ throughout the experiment. Sample weight was $15 \mathrm{~g}$ and test was carried out in triplicate. Flow properties were investigated by measuring the dynamic viscosity $(\eta, \mathrm{Pa} / \mathrm{s})$ as a function of time for $60 \mathrm{~min}$ in addition to measurment of viscosity as a function of shear rate (ranging from $0.1 \mathrm{~s}^{-1}$ to $200 \mathrm{~s}^{-1}$ ) [11].

\section{Measurement of $\mathrm{pH}$}

Using the Mettler Toledo $320 \mathrm{pH}$ meter (Switzerland), the $\mathrm{pH}$ values of the samples were measured at $25 \pm 1^{\circ} \mathrm{C}$. The measurements were carried out in triplicate.

\section{Refractive index measurement}

A refractometer (Abbe refractometer, ATAGO, Japan) was used to determine the refractive indices of the formulations in triplicate at $25{ }^{\circ} \mathrm{C}$ [12].

\section{Zeta-potential measurement}

A laser doppler electrophoresis was carried out on the microemulsions with a Zetasizer Nano Series equipment (Malvern Instruments, UK), which is capable of measuring sizes between 0.6 and $6000 \mathrm{~nm}$. Zeta potential and the dynamic light scattering (DLS) of the microemulsions were analysed in triplicate at $25^{\circ} \mathrm{C}$ [13].

\section{Differential scanning calorimetry (DSC)}

A Mettler Toledo DSC822 was used to carry out the thermal analysis. The samples were cooled from 25 to $-50{ }^{\circ} \mathrm{C}$ at a cooling rate of $5{ }^{\circ} \mathrm{C} / \mathrm{min}$, held for $3 \mathrm{~min}$ at $-50{ }^{\circ} \mathrm{C}$, and heated from -50 to $50^{\circ} \mathrm{C}$ at a heating rate of $10^{\circ} \mathrm{C} / \mathrm{min}$. Heating was carried out under nitrogen gas at a flow rate of 50 $\mathrm{ml} / \mathrm{min}[14]$.

\section{Stability study}

Samples of selected microemulsions were centrifuged at $13,000 \mathrm{rpm}$ for $30 \mathrm{~min}$ at $25 \pm 1{ }^{\circ} \mathrm{C}$ to determine their thermodynamic stability [15]. The stability of the microemulsions was assessed by visual inspection of the samples stored in tightly closed tubes at room temperature $\left(25 \pm 1{ }^{\circ} \mathrm{C}\right)$ in the dark for any physical changes daily in the first week and then weekly for another four weeks [15].

\section{RESULTS}

\section{Phase diagram}

The formation of microemulsion systems is indicated by the shaded area in the phase diagrams while the turbid liquid with multiphase systems is depicted by the area outside the shaded area (Figs $1-3$ ).

\section{Effect of surfactant}

The system containing the four polyoxyethylene sorbitan esters - Tween 20, 40, 60 and 80 - had labeled (by manufacturers) HLB values of 16.7 , 15.6, 14.9 and 15 , respectively. The ratio of Tween to 1-butanol was kept constant at 1:1. The effect of surfactant type on microemulsion area is shown in Figure 1 and indicates that the best surfactant to produce microemulsion is in the following rank order: Tween $80>$ Tween $60>$ Tween 40 > Tween 20 .

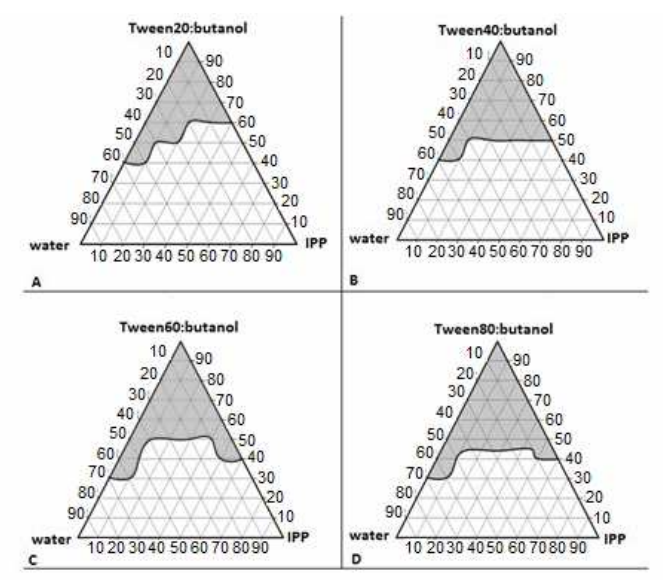

Figure 1: Effect of surfactant type on formation of microemulsions. Note: A = Tween 20, B = Tween 40, $\mathrm{C}=$ Tween $60, \mathrm{D}=$ Tween 80 


\section{Effect of cosurfactant}

Five linear alcohol types were used as cosurfactants in order to study their effects on the phase behavior of the microemulsion system. The ratio of Tween 80 to 1 -butanol was kept constant at 1:1. The finding derived from Figure 2 indicates that the most suitable cosurfactant is in the following rank order: 1 -butanol $>1$-pentanol $>$ 1-propanol $>1$-ethanol $=1$-methanol.
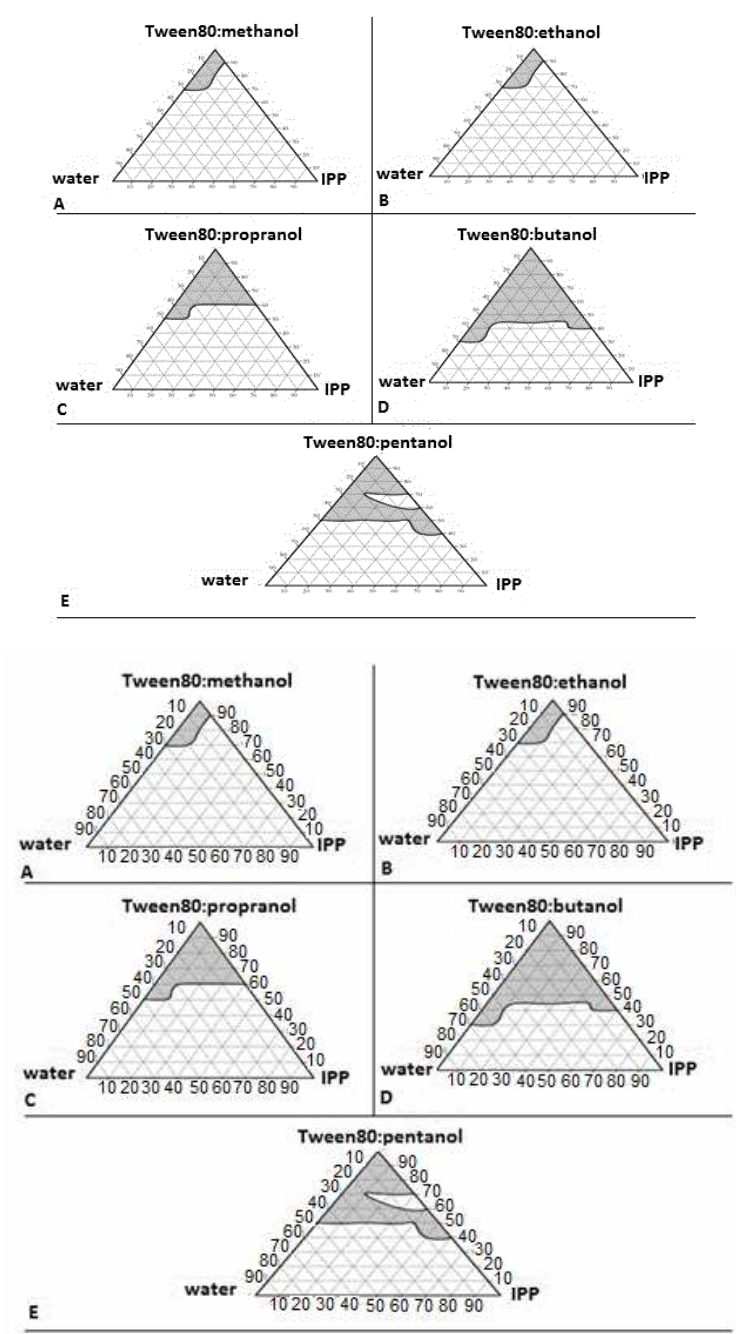

Figure 2: Effect of cosurfactant type on formation of microemulsions. Note: $\mathrm{A}=$ methanol, $\mathrm{B}=$ ethanol, $\mathrm{C}=$ propanol, $\mathrm{D}=$ butanol, $\mathrm{E}=$ pentanol

\section{Effect of surfactant/cosurfactant ratio}

After the selection of the surfactant and cosurfactant mixture that produced the highest volume of microemulsions, viz, Tween 80/1butanol, one important factor affecting the formation of microemulsion area was surfactant/cosurfactant ratio. The phase diagrams constructed for the systems at various ratios $(1: 1,2: 1,3: 1,4: 1$, and $1: 0)$ are shown in Figure 3 and it reveals the rank order as $3: 1>$ $2: 1>1: 1>4: 1>1: 0$. Thus, the optimum surfactant/cosurfactant ratio for the microemulsion systems was 3:1.
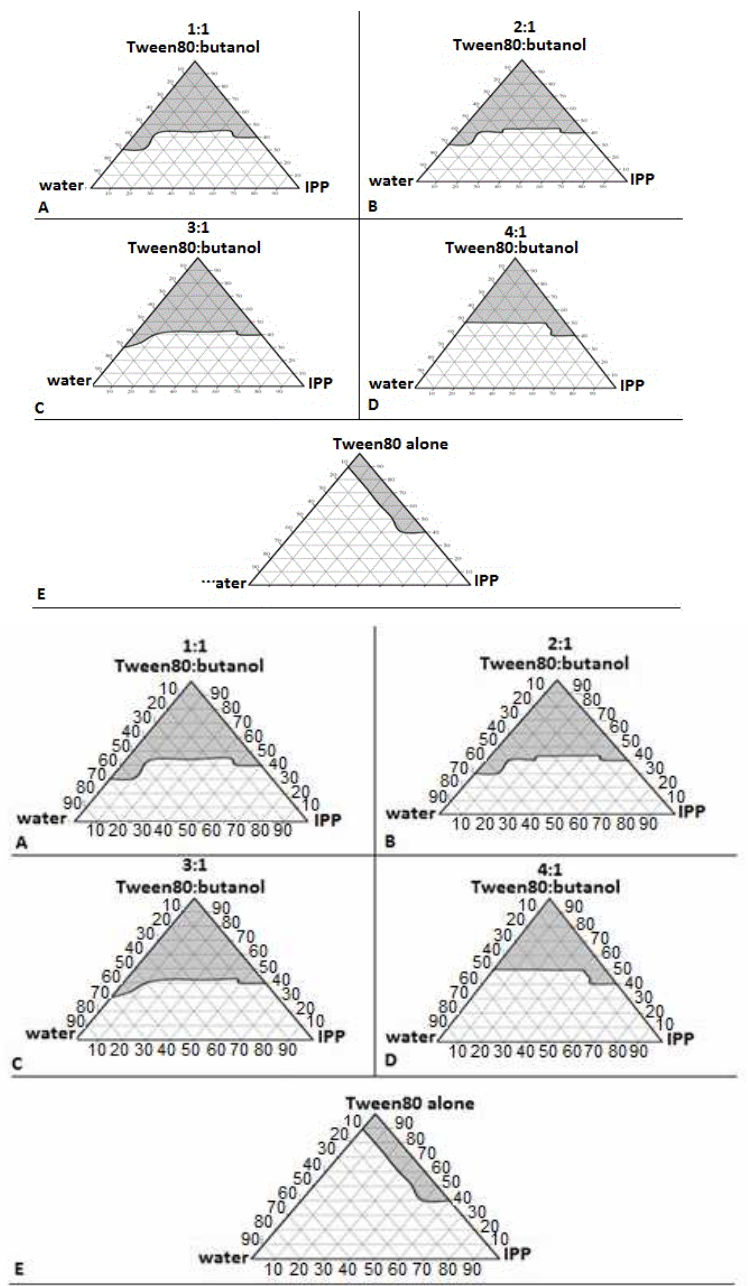

Figure (3): Effect of ratio of surfactant to cosurfactant on the formation of microemulsions. Note: $A=1: 1, B=$ $2: 1, C=3: 1, D=4: 1, E=1: 0$.

\section{Microemulsion type}

The microscopic analysis of microemulsion using dye indicates that the microemulsion type was $\mathrm{w} / \mathrm{o}$ at water volume fraction $<15 \% \mathrm{w} / \mathrm{w}$, and $\mathrm{o} / \mathrm{w}$ at water volume fraction $>25 \% \mathrm{w} / \mathrm{w}$. The electrical conductivity of the selected microemulsion samples was measured as a function of water percentage which indicated that water in oil microemulsion is formed at a low volume fraction of water, below $15 \%$. Conductivity results show the formation of three structural regions, namely, w/o (water volume fraction $<15 \% \mathrm{w} / \mathrm{w}$, bicontinuous (water volume fraction $15-25 \% \mathrm{w} / \mathrm{w}$, and o/w (water volume fraction $>25 \% \mathrm{w} / \mathrm{w}$.

The physicochemical data for selected microemulsions are given in Table 1. $\mathrm{pH}$ ranged from 6.76 to 7.80 , while the refractive indices 
Table 1: Physicochemical characteristics of microemulsions (mean \pm SD)

\begin{tabular}{lccccccc}
\hline Sample & $\begin{array}{c}\text { Water } \\
\text { no. }\end{array}$ & $\begin{array}{c}\text { Oil } \\
(\%)\end{array}$ & $\begin{array}{c}\text { Surfactant: } \\
\text { cosurfactant } \\
(\mathbf{3 : 1 )}\end{array}$ & $\mathbf{P H}$ & $\begin{array}{c}\text { Refractive } \\
\text { index }\end{array}$ & $\begin{array}{c}\text { potential } \\
(\mathbf{m V})\end{array}$ & $\begin{array}{c}\text { Droplet size } \\
(\mathbf{n m})\end{array}$ \\
\hline 1 & 5 & 50 & 45 & $7.56 \pm 0.01$ & $1.438 \pm 0.002$ & $-42 \pm 2$ & $129 \pm 2$ \\
\hline 2 & 10 & 45 & 45 & $7.77 \pm 0.01$ & $1.435 \pm 0.003$ & $-39 \pm 3$ & $136 \pm 3$ \\
\hline 3 & 15 & 40 & 45 & $7.80 \pm 0.02$ & $1.430 \pm 0.001$ & $-41 \pm 3$ & $147 \pm 1$ \\
\hline 4 & 20 & 35 & 45 & $7.54 \pm 0.01$ & $1.423 \pm 0.001$ & $-43 \pm 1$ & $145 \pm 2$ \\
\hline 5 & 25 & 30 & 45 & $7.45 \pm 0.02$ & $1.418 \pm 0.002$ & $-44 \pm 2$ & $106 \pm 4$ \\
\hline 6 & 30 & 25 & 45 & $7.25 \pm 0.02$ & $1.411 \pm 0.001$ & $-32 \pm 4$ & $94.0 \pm 2$ \\
\hline 7 & 35 & 20 & 45 & $7.09 \pm 0.01$ & $1.407 \pm 0.002$ & $-45 \pm 4$ & $56.0 \pm 1$ \\
\hline 8 & 40 & 15 & 45 & $7.04 \pm 0.01$ & $1.401 \pm 0.001$ & $-48 \pm 1$ & $46.0 \pm 3$ \\
\hline 9 & 45 & 10 & 45 & $6.92 \pm 0.01$ & $1.396 \pm 0.003$ & $-75 \pm 3$ & $42.0 \pm 4$ \\
\hline 10 & 50 & 5 & 45 & $6.76 \pm 0.02$ & $1.390 \pm 0.002$ & $-47 \pm 2$ & $26.0 \pm 1$ \\
\hline
\end{tabular}

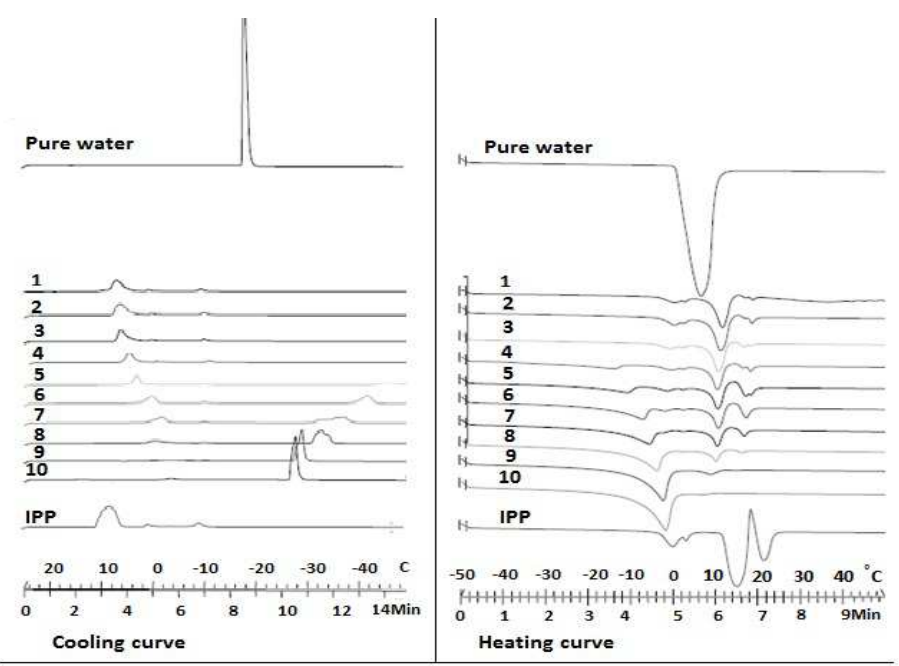

Figure 4: DSC thermogram of pure water, pure IPP, and microemulsions (numbered 1 - 10)

values of samples gradually decreased as the concentration of water increased and the oil phase decrease. At the same time, the refractive indices for the first three samples (which are w/o microemulsion type) were higher than those of $\mathrm{o} / \mathrm{w}$ and bicontinuous microemulsions. and this is caused by the higher refractive index of IPP as external pseudophase, compared to that of water as external pseudophase.

The microemulsion systems were negatively charged, and their droplet size was $<150 \mathrm{~nm}$ which confirm the formation of transparent microemulsion. Droplet size gradually increased as the concentration of water in the samples increased. When the system transited from w/o to bicontinuous and $\mathrm{o} / \mathrm{w}$, the droplet began to decrease. with increase of the water concentration and this was caused by $t$ increase in the concentration of external phase (water), and leading to a decrease in the concentration of the internal phase (oil). Viscosity results at different shear rates indicate Newtonian flow behavior.

\section{Thermal properties}

DSC results (Figure 4) indicate that pure water showed an exothermic peak at $-18.76{ }^{\circ} \mathrm{C}$ (freezing) upon cooling, while the heating thermogram showed an endothermic peak at $0.36{ }^{\circ} \mathrm{C}$ (melting). These thermal events were absent from the thermograms of microemulsions containing $<30 \%$ but were present water content was $\geq 30 \%$.

\section{Stability study}

No significant change $(p>0.05)$ was found in the initial droplet size $(92.7 \mathrm{~nm})$ of the microemulsions upon storage for 4 weeks; therefore, it is assumed that no droplet coalescence and/or aggregation occurred. Moreover, no color change and phase separation were observed, indicating that these microemulsions were stable on storage. 


\section{DISCUSSION}

With the help of polarized light microscopy, liquid crystalline phases could easily be distinguished by presence of a birefringence area (double refraction) due to their anisotropic nature, which show that some areas appear light and others appear dark, while microemulsion phases show only dark area under polarized light microscope. The formation of a microemulsion system is largely determined by the type of surfactant, and so it could be concluded that the number of carbons that presents in the fatty acid side chain of the surfactant has a direct correlation with the formation of microemulsion. Meanwhile, Tween 80 produced a higher volume of microemulsion than Tween 60, although both have the same number of carbon chain. These results are in a good agreement with those obtained by Cho et al and Sintov et al $[16,17]$.

The addition of cosurfactant is crucial to obtain a microemulsion system. The gradual reduction in microemulsion area in the ternary diagram towards the shorter chain of the cosurfactant alcohols is due to the fact that shorter chain alcohols are soluble in the aqueous phase and when used as cosurfactants, they become ineffective. Therefore, 1-butanol was considered as best cosurfactant for the preparation of microemulsion. These results are in good agreement with the work done by Nandi et al [18]. It is noteworthy that the microemulsion containing Tween 80:1-butanol (3:1) exhibited acceptable $\mathrm{pH}$, small droplet size, negative charge, and stability during extended storage.

\section{CONCLUSION}

A stable microemulsion can be prepared by using the optimum combination of IPP with Tween 80 and 1- butanol which has a potential as a suitable drug delivery system.

\section{ACKNOWLEDGEMENT}

The authors wish to thank Department of pharmacy, Faculty of Medicine, University of Malaya, for its financial support of this work.

\section{REFERENCES}

1. Danielsson I, Lindman B. The definition of microemulsion. Colloid Surf. 1981; 3: 391-392.

2. Hoar TP, Schulman JH. Transparent water in oil dispersions: the oleopathic hydromicelle. Nature.1943; 152: 102-103.
3. Warisnoicharoen W, Lansley AB, Lawrence MJ. Nonionic oil-in-water microemulsions: the effect of oil type on phase behaviour. Int J Pharm. 2000; 198(1): 7-27.

4. Lawrence MJ, Rees GD. Microemulsion-based media as novel drug delivery systems. Adv. Drug Deliv. Rev. 2000; 45: 89-121.

5. Nirmala G, Padmini R, Rashmi M. Microemulsions for topical use - a review. Ind J Pharm Edu Res. 2011; 45( 1): 100-107

6. Salmiah A. Non-food uses of palm oil and palm kernel oil. MPOPC palm oil information series, Kuala Lumpur. 2000; p. 24.

7. El-nokaly M, Hiler G, McGrady J. Solubilization of water and water-soluble compounds in triglycerides. In El-Nokaly, M. and Cornell, D. (ed), Microemulsions and emulsions in foods. Washington DC: Am. Chem. Soc. 1991; p. 2643.

8. Bagwe RP, Kanicky JR, Palla BJ, Patanjali PK, and Shah DO. Improved drug delivery using microemulsions: Rationale, recent progress and new horizons. Crit. Rev. Ther. Drug. Car .Sys. 2001; 18(1): 77-140.

9. Biruss $B$, Valenta $C$. The advantage of polymer addition to a non-ionic oil in water microemulsion for the dermal delivery of progesterone. Int. J. Pharm. 2008; 349: 269-273.

10. Podlogar F, Gasperlin M, Tomsic M, Jamnik $A$, and Bester-Rogac M. Structural characterisation of water-Tween 40 (R)/Imwitor 308 (R)-isopropyl myristate microemulsions using different experimental methods. Int. J. Pharm. 2004; 276: 115-128.

11. Djordjevic L, Primorac $M$, Stupar $M$, and Krajisnik $D$. Characterization of caprylocaproyl macrogolglycerides based microemulsion drug delivery vehicles for an amphiphilic drug. Int. J. Pharm. 2004; 271: 11-19.

12. Aboofazeli R, Barlow DJ, and Lawrence MJ. Particle size analysis of concentrated phospholipid microemulsions: 1.Total intensity light scattering. AAPS PharmSci. 2000; 2(2): 27-39.

13. Lee J, Lee Y, Kim J, Yoon M, Choi YW. Formulation of microemulsion systems for transdermal delivery of aceclofenac. Arch.Pharm.Res. 2005; 28 (9): 1097-1102.

14. Boonme P, Krauel K, Graf A, Rades T, Junyaprasert VB. Characterization of microemulsion structure in the pseudoternary phase diagram of isopropyl palmitate/water/Brij 97:1-butanol. AAPS PharmSciTech. 2006; 7(2): E45-53

15. Fahima MH, Dalia SS, Mohamed KG, Mohamed N, Aliaa I. Formulation, Characterization, and Clinical Evaluation of Microemulsion Containing Clotrimazole for Topical Delivery. AAPS PharmSciTech. 2011; 12(3): 879-886.

16. Cho YH, Kim S, Bae EK, Mok CK, Park J. Formulation of a cosurfactant free $\mathrm{O} / \mathrm{w}$ microemulsion using nonionic surfactant mixtures. J. Food Science. 2008; 73(3): E115-121.

17. Sintov AC, Shapiro L. New microemulsion vehicle facilitates percutaneous penetration in vitro and cutaneous drug bioavailability in vivo. Journal of Controlled Release. 2004; 95: 173-183.

18. Nandi I, Bari M, Joshi H. Study of isopropyl myristate microemulsion systems containing cyclodextrins to improve the solubility of 2 model hydrophobic drugs. AAPS Pharm.Sci.Tech. 2003; 4 (1): 71-79. 